Pesq. Vet. Bras. 37(1):1-7, janeiro 2017 DOI: 10.1590/S0100-736X2017000100001

\title{
Tristeza Parasitária em bovinos do semiárido pernambucano ${ }^{1}$
}

\author{
Grace B. Santos², Iara M.M. Gomes², Júlia A.G. Silveira3, Larissa C.S.R. Pires², Sérgio \\ S. Azevedo ${ }^{4}$, Alexandre C. Antonelli ${ }^{2}$, Múcio F.B. Ribeiro ${ }^{3}$ e Mauricio C. Horta ${ }^{2 *}$
}

\begin{abstract}
Santos G.B., Gomes I.M.M., Silveira J.A.G., Pires L.C.S.R., Azevedo S.S., Antonelli A.C., Ribeiro M.F.B. \& Horta M.C. 2017. [Cattle Tick Fever in semi-arid of Pernambuco.] Tristeza Parasitária em bovinos do semiárido pernambucano. Pesquisa Veterinária Brasileira 37(1):1-7. Laboratório de Doenças Parasitárias, Universidade Federal do Vale do São Francisco, Campus de Ciências Agrárias, Rodovia BR-407 Km 12, Lote 543, Projeto de Irrigação Senador Nilo Coelho s/n, C1, Petrolina, PE 56300-990, Brazil. E-mail: horta.mc@hotmail.com

This study aimed to determine the seroprevalence of Babesiosis and Anaplasmosis in cattle from the municipalities of Ouricuri and Petrolina, state of Pernambuco, Brazil, and to define the risk factors for the occurrence of the diseases. Blood samples were collected for serologic testing by Indirect Immunofluorescence Assay (IFA). Sanitary epidemiological questionnaires were applied to the producers aiming to identify possible risk factors. Ticks were collected, identified and tested by Polymerase Chain Reaction (PCR) for the diagnosis of infection by Anaplasma marginale, Babesia bigemina and Babesia bovis. The study was conducted with 861 cattle, being 468 in Petrolina and 393 in Ouricuri. The seroprevalence of A. marginale, B. bigemina and B. bovis in Petrolina was of 35.0\% (164/468), 35.9\% (168/468) and 32.3\% (151/468), respectively; and in Ouricuri was 45.5\% (179/393), $38.6 \%$ (152/393), and 54.9\% (216/393), respectively. Co-infection for Anaplasma spp. and Babesia spp. was observed in $31.6 \%$ and $32.1 \%$ samples of Petrolina and Ouricuri, respectively. The detection of DNA of Babesia spp. by PCR was possible in 5.8\% (8/137) ticks; which $62.5 \%$ (5/8) was detected later infection with B. bovis; and 23.3\% (32/137) with $A$. marginale. The presence of ticks, the use of acaricide, age, race, and county of residence of the animals were identified as risk factors for TBD by univariate analysis and multivariate. This study allowed the characterization of the municipalities studied as enzootic instability areas for these hemoparasitic, and consequently alert for adoption of adequate control measures and new studies.
\end{abstract}

INDEX TERMS: Cattle Tick Fever, semi-arid of Pernambuco, Babesia bigemina, Babesia bovis, Anaplasma marginale, epidemiology.

RESUMO.- Este estudo objetivou determinar a soroprevalência da Babesiose e Anaplasmose em bovinos dos municípios de Ouricuri e Petrolina, estado de Pernambuco, Bra-

\footnotetext{
${ }^{1}$ Recebido em 22 de agosto de 2015.

Aceito para publicação em 5 de julho de 2016.

${ }^{2}$ Laboratório de Doenças Parasitárias, Universidade Federal do Vale do São Francisco (Univasf), Campus de Ciências Agrárias, Rodovia BR-407 Km 12, Lote 543, Projeto de Irrigação Senador Nilo Coelho s/n, C1, Petrolina, PE 56300-990, Brasil. *Autor para correspondência: horta.mc@ hotmail.com

${ }^{3}$ Departamento de Parasitologia, Instituto de Ciências Biológicas, Universidade Federal de Minas Gerais (UFMG), Cx. Postal 3037, Belo Horizonte, MG 30270-901, Brasil.

${ }^{4}$ Unidade Acadêmica de Medicina Veterinária, Centro de Saúde e Tecnologia Rural, Universidade Federal de Campina Grande (UFCG), Av. Universitária s/n, Bairro Santa Cecília, Cx. Postal 64, Patos, PB 58700-970, Brasil.
}

sil; e definir os possíveis fatores de risco para a ocorrência dessas doenças. Amostras de sangue foram coletadas para realização de teste sorológico por Imunofluorescência Indireta (RIFI). Questionários epidemiológicos sanitários foram aplicados aos produtores com o objetivo de identificar possíveis fatores de risco. Carrapatos foram coletados, identificados e testados por Reação em Cadeia da Polimerase (PCR) para o diagnóstico da infecção por Anaplasma marginale, Babesia bigemina e Babaesia bovis. 0 estudo foi conduzido com 861 bovinos, sendo 468 de Petrolina e 393 de Ouricuri. A soroprevalência de A. marginale, B. bigemina e $B$. bovis em Petrolina foi de 35,0\% (164/468), 35,9\% (168/468) e $32,3 \%$ (151/468), respectivamente; e em Ouricuri foi de $45,5 \%(179 / 393), 38,6 \%(152 / 393)$ e $54,9 \%$ (216/393), respectivamente. A co-infecção por Anaplasma 
spp. e Babesia spp. foi observada em $31,6 \%$ e $32,1 \%$ de amostras de Petrolina e Ouricuri, respectivamente. A detecção de DNA de Babesia spp. por PCR foi possível em 5,8\% (8/137) carrapatos, dos quais em 62,5\% (5/8) foi detectada posteriormente infecção por B. bovis, e em $23,3 \%$ (32/137) por A. marginale. A presença de carrapatos, o uso de acaricidas, idade, raça, e o município de residência dos animais foram identificados como fatores de risco para TPB pela análise univariável e multivariável. Este estudo permitiu caracterizar os municípios estudados como de instabilidade enzoótica para esses hemoparasitos, e consequentemente, alertar para adoção de medidas adequadas de controle e realização de novos estudos.

TERMOS DE INDEXAÇÃO: Tristeza Parasitária, bovinos, semiárido pernambucano, Babesia bigemina, Babesia bovis, Anaplasma marginale, epidemiologia.

\section{INTRODUÇÃO}

A Tristeza Parasitária Bovina (TPB) é causada pelos hemoprotozoários Babesia bovis e Babesia bigemina, e pela bactéria Anaplasma marginale. Essas enfermidades apresentam epidemiologia e sinais clínicos muito similares, sendo responsáveis por perdas econômicas na pecuária mundial e brasileira (Bock et al. 2004, Kocan et al. 2010).

Rhipicephalus (Boophilus) microplus é o principal vetor biológico para os três agentes, com ampla distribuição em regiões tropicais e subtropicais (Guglielmone 1995). A Anaplasmose pode também ser transmitida mecanicamente por dípteros hematófagos e de forma iatrogênica, através de fômites contendo sangue contaminado (Kocan et al. 2010).

Dentre os principais sinais clínicos apresentados pelos animais, destacam-se anemia hemolítica progressiva, icterícia, febre, apatia, inapetência e taquipnéia. Observam-se também aborto, relatado na anaplasmose; além de hemoglobinemia e hemoglobinúria, observados na babesiose, que geralmente evoluem para a morte do animal (Bock et al. 2004, Kocan et al. 2010).

A dinâmica da infecção é dependente de fatores como a população de carrapatos, sua capacidade de transmissão, e a susceptibilidade dos bovinos, que pode variar de acordo com a raça, idade, estado fisiológico e imunológico dos animais (Dreher et al. 2005, Kocan et al. 2010).

O Brasil é reconhecido como um país enzoótico para TPB. No entanto, existem regiões que em função de suas condições edafoclimáticas não favorecem o desenvolvimento do carrapato durante todo o ano. Este leva ao desenvolvimento de áreas de instabilidade enzoótica para TPB de acordo com conceitos de Mahoney \& Ross (1972). É conhecido que as maiores perdas econômicas referentes à TPB ocorrem em áreas de instabilidade enzoótica ou por ocasião da transferência de animais destas, ou de áreas livres, para outras cuja situação epidemiológica seja de estabilidade.

O diagnóstico destas enfermidades baseia-se na pesquisa direta do agente em esfregaços sanguíneos na fase aguda da doença (Böse et al. 1995, Bock et al. 2004), além de métodos sorológicos como a Reação de Imunofluorescência
Indireta (RIFI) e moleculares como a PCR (Costa-Júnior et al. 2006), mais empregadas na fase crônica.

0 estudo epidemiológico da babesiose e da anaplasmose bovina em uma determinada área pode revelar a possibilidade da ocorrência ou não de surtos. Tal possibilidade é avaliada segundo a situação epidemiológica da região estudada. Em regiões semiáridas do Nordeste há escassez de estudos sobre a situação epidemiológica da babesiose e anaplasmose. Desta forma, estudos em áreas geográficas distintas fazem-se necessários para ampliação do conhecimento acerca da epidemiologia da TPB em cada região, principalmente devido à diversidade climática.

Este estudo objetivou verificar os aspectos epidemiológicos da babesiose e anaplasmose bovina, referente à infecção em bovinos e carrapatos, como também definir os possíveis fatores de risco para a ocorrência dessas doenças em municípios localizados no semiárido pernambucano.

\section{MATERIAL E MÉTODOS}

Local de estudo. 0 estudo foi realizado em propriedades rurais dos municípios de Petrolina e Ouricuri, localizados em áreas de clima tropical semiárido no estado de Pernambuco, Brasil. Petrolina detém aproximadamente 18.500 cabeças de bovinos e está localizada na mesorregião do São Francisco, ocupando uma área territorial de $4.558,537 \mathrm{~km}^{2}$. 0 índice pluviométrico médio é de 431,8 mm anuais (IBGE 2010). Ouricuri concentra aproximadamente 30.500 cabeças de bovinos e localiza-se na mesorregião do Sertão pernambucano, ocupando uma área de 2.422,882 $\mathrm{km}^{2}$. A precipitação média mensal varia entre 5 e 140mm (IBGE 2010).

Colheita de sangue. No período de agosto de 2011 a abril de 2013, foram avaliados 861 bovinos, sendo 468 do município de Petrolina provenientes de 19 propriedades rurais, e 393 do município de Ouricuri, oriundos de 13 propriedades. 0 cálculo da amostragem foi determinado considerando 95\% de confiança, erro de $7 \%$ e prevalência da doença estimada em $50 \%$. Os animais foram escolhidos de forma aleatória, sendo utilizados para esse estudo animais com idade acima de seis meses. Aproximadamente 92,9\% (800/861) dos bovinos apresentavam idade $>1$ ano, sendo 92,7\% (434/468) em Petrolina e 93,1\% (366/393) em Ouricuri. Amostras de sangue dos animais foram colhidas por venopunção em tubos sem anticoagulante. Após centrifugação o soro foi aliquotado em tubos de $1,5 \mathrm{~mL}$ e estocado a $-20^{\circ} \mathrm{C}$.

0 presente estudo foi submetido e aprovado pelo Comitê de Ética em Estudos Humanos e Animais da Universidade Federal do Vale do São Francisco, protocolo 0010/261011.

Diagnóstico sorológico. A presença de anticorpos anti- $B$. bigemina, anti-B. bovis e anti-Anaplasma marginale foi detectada empregando-se a Reação de Imunofluorescência Indireta (RIFI), utilizando anticorpo monoclonal anti-bovino (AbD Serotec) conjugado ao isotiocianato de fluoresceína (FITC). Antígenos de $A$. marginale (cepa UFMG1); Babesia bigemina (cepa BbigMG); e $B a$ besia bovis (cepa BbovMG) (Bastos et al. 2010) foram confeccionadas conforme recomendações do IICA (1987). As amostras foram consideradas positivas se apresentaram fluorescência na diluição de 1:40. Para cada reação foi utilizado soro controle positivo e negativo (Bastos et al. 2010).

Análises moleculares. A extração de DNA dos carrapatos foi realizada conforme protocolo padronizado por Horta et al. (2007), com maceração dos artrópodes em microtubos, com auxílio de ponteiras adaptadas. As amostras foram processadas individualmente e/ou em "pools" conforme a disponibilidade. Foram 
separados aleatoriamente 62 carrapatos individuais (20 provenientes de animais de Petrolina e 42 de animais de Ouricuri) e 75 "pools" de carrapatos (27 provenientes de Petrolina e 48 de Ouricuri), cada "pool" contendo quatro carrapatos (total $=300$ carrapatos), totalizando 137 amostras (47 oriundas de Petrolina e 90 de Ouricuri). Os carrapatos foram submetidos à extração com kit comercial Wizard ${ }^{\circledR}$ Genomic DNA Purification (Promega, Madison, WI, USA), para um volume final de $75 \mu \mathrm{L}$ para os "pools" e 50 $\mu \mathrm{L}$ para extração de carrapatos individuais.

Visando a amplificação de DNA de Babesia spp. foram testadas sequências de oligonucleotídeos que consistem na amplificação de fragmentos de DNA de 551 pares de base do gene 18S rRNA de Babesia spp. de acordo com Almeida (2011): BAB 143-167 [5'CCG TGC TAA TTG TAG GGC TAA TAC A-3'] e BAB 694-667 [5'-GCT TGA AAC ACT CTA RTT TCT CAA AG-3']. As reações foram realizadas em volume final de $25 \mu \mathrm{L}$, contendo $11,0 \mu \mathrm{L}$ de água ultra purificada; $4,0 \mu \mathrm{L}$ de $2 \mathrm{mM}$ mix dNTP (Invitrogen ${ }^{\circledR}$ ); $0,75 \mu \mathrm{L}$ de $25 \mathrm{mM}$ $\mathrm{MgCl}^{2}$ (Invitrogen ${ }^{\circledR}$ ); 2,5 $\mu \mathrm{L}$ de buffer 10x (Invitrogen ${ }^{\circledR}$ ); $1,25 \mu \mathrm{L}$ de cada oligonucleotídeo iniciador, $0,25 \mu \mathrm{L}(1 \mathrm{U})$ de Taq DNA polimerase (Invitrogen ${ }^{\circledR}$ ); e $4 \mu \mathrm{L}$ da amostra de DNA. Para cada reação, foi adicionado um controle positivo (DNA Babesia spp.) e um controle negativo (água ultra purificada). As condições de amplificação foram: desnaturação inicial a $95^{\circ} \mathrm{C}$ por 5 minutos, seguida por 35 ciclos de $95^{\circ} \mathrm{C}$ por 30 segundos para desnaturação, $58^{\circ} \mathrm{C}$ por 30 segundos para anelamento, $72^{\circ} \mathrm{C}$ por 30 segundos para extensão e $72^{\circ} \mathrm{C}$ por 7 minutos para extensão final.

Posteriormente, as amostras positivas para Babesia spp. foram submetidas a uma nova reação utilizando primers específicos para B. bovis e B. bigemina (Costa 2013). Na PCR para B. bovis, foram utilizados os primers Bbo(F) [5'-CGA GGA AGG AAC TAC CGA TGT TGA ATA TC-3'] e Bbo(R) [5'-CAA CGT ACG AGG TCA AGC TAC CGA GCA G-3'], que amplificam um fragmento de 347-pb específico para o gene de roptria (rap-1) de B. bovis. Na PCR para B. bigemina, foram utilizados os primers Bbi(F) [5'-GGG ACG TCA AGC GAT TTT GAG ACG T-3'] e Rbi(R) [5'-GAG TGT TGC TGA TTG ACG ACC TAA GCG C-3'], que amplificam um fragmento de 340-pb específico para o gene de roptria (rap-1) de B. bigemina. Visando a PCR para amplificação de DNA de $A$. marginale, foram empregados os seguintes primers Am1(F) [5'-CAA TCG TGA GGG ATA GCC TTG TAC-3'] e Am1(R) [5'-TGG TAT CAC GGT CAA AAT CTT TGC T-3'], que amplificam um fragmento de 300-pb específico para o gene msp1a de A. marginale (Costa 2013). Todas as reações foram realizadas nas mesmas condições de reagentes e ciclos térmicos. Para tal, cada tubo de reação consistiu num volume total final de $25 \mu \mathrm{L}$, com uma mistura contendo $12,6 \mu \mathrm{L}$ de água ultrapura, $2,5 \mu \mathrm{L}$ de tampão, 2,5 $\mu \mathrm{L}$ de amostra de DNA dos carrapatos, $4,0 \mu \mathrm{L}$ de $\mathrm{dN}$ TPs, $0,75 \mu \mathrm{L}$ de $\mathrm{MgCl}_{2}, 1,25 \mu \mathrm{L}$ de cada primer e $0,15 \mu \mathrm{L}$ de enzima Taq-polimerase (Taq-Platinum, Invitrogen). As condições de PCR foram $95^{\circ} \mathrm{C}$ por $5 \mathrm{~min}$., seguido de 40 ciclos de $95^{\circ} \mathrm{C}$ por 15 seg., $58^{\circ} \mathrm{C}$ por 30 seg., $72^{\circ} \mathrm{C}$ por 30 seg.; e extensão final a $72^{\circ} \mathrm{C}$ por 5 $\min$.

As amostras foram amplificadas em aparelho termociclador (Biocycler ${ }^{\circledR}$ ) e os produtos amplificados na PCR foram submetidos à eletroforese em gel de Agarose a 1,5\%, sob $100 \mathrm{~V}$ ( $\cong 1$ hora) corado por Brometo de etídeo (30 minutos). As bandas de DNA separadas por meio de eletroforese foram visualizadas em transluminador de luz ultravioleta. Foram consideradas positivas as amostras com produto amplificado correspondente ao mesmo padrão de migração da banda gerada pelo controle positivo correspondente.

Determinação de Fatores de Risco: No momento da visita às propriedades, foi aplicado um questionário para avaliar as condições sanitárias e epidemiológicas, objetivando a identificação de possíveis fatores de risco da doença na região. A análise de fatores de risco foi conduzida em duas etapas: análise univariável e análise multivariável. $\mathrm{Na}$ análise univariável, cada variável independente foi cruzada com a variável dependente (resultado da sorologia: negativo $=0$; positivo $=1$ ), e aquelas que apresentaram valor de $p \leq 0,20$ pelo teste de qui-quadrado ou teste exato de Fisher foram selecionadas para a análise multivariável, utilizando-se regressão logística múltipla. 0 nível de significância adotado na análise múltipla foi de $5 \%$. Todas as análises foram realizadas com o programa SPSS 20.0 for Windows.

\section{RESULTADOS}

Nas amostras de Petrolina, a frequência de anticorpos anti-Anaplasma marginale, anti-Babesia bigemina e anti-Babesia bovis detectada pela RIFI foi de $35,0 \%, 35,9 \%$ e $32,3 \%$, respectivamente. Foi verificada co-infecção por Babesia spp. e A. marginale em 148 (31,6\%) das amostras analisadas. Em Ouricuri, $45,5 \%$ das amostras foram positivas para A. marginale, $38,6 \%$ para B. bigemina e $54,9 \%$ para B. bovis, observando-se co-infecção de Babesia spp. e A. marginale em 32,1\% dos animais (Quadro 1). À análise individual das propriedades, foi observada a ocorrência de condições epidemiológicas diferentes nos municípios estudados.

De acordo com a idade dos animais, foi constatado na RIFI que a maior frequência de bovinos positivos para anaplasmose ocorre na faixa etária de 37 e 48 meses $(52,6 \%)$ e de menor positividade na de 6-12 meses (33,3\%). Com relação à Babesiose, a maior frequência de $B$. bovis e $B$. bigemina foi observada na faixa de 48-60 meses $(50,8 \%)$ e de $25-36$ meses $(43,8 \%)$ respectivamente, enquanto a menor positividade ocorre na faixa de 6-12 meses tanto para $B$. bovis $(22,8 \%)$ como para B. bigemina $(26,7 \%)$. Os bovinos das raças Nelore, Girolando e os animais mestiços foram os que apresentaram maior positividade para $A$. marginale, $B$. bovis e B. bigemina. De acordo com o sexo dos animais, as fêmeas apresentaram maior soroprevalência para os hemoparasitas analisados.

A infestação por carrapatos foi verificada em $15,8 \%$ das propriedades de Petrolina, sendo que $16,2 \%$ dos animais encontravam-se infestados. Neste município foi observado que em $84,2 \%$ das propriedades foi relatada a presença de dípteros hematófagos (tabanídeos e/ou mosca do chifre). Em Ouricuri, foi constatada maior percentagem de proprie-

Quadro 1. Número e frequência de anticorpos anti-Anaplasma marginale, anti-Babesia bovis e anti-Babesia bigemina em amostras de soro sanguíneo de bovinos das propriedades rurais dos municípios de Petrolina e Ouricuri, PE, utilizando a RIFI

\begin{tabular}{lccccc}
\hline Município & $\begin{array}{c}\mathrm{N}^{\circ} \text { de animais reagentes } \\
\text { para B. bigemina (\%) }\end{array}$ & $\begin{array}{c}\mathrm{N}^{\circ} \text { de animais reagentes } \\
\text { para B. bovis (\%) }\end{array}$ & $\begin{array}{c}\mathrm{N}^{\circ} \text { de animais reagentes } \\
\text { para } \text { A. marginale (\%) }\end{array}$ & $\begin{array}{c}\text { Co-infecção Babesia spp. } \\
+ \text { A. marginale (\%) }\end{array}$ & $\begin{array}{c}\mathrm{N} \text { o de animais } \\
\text { amostrados }\end{array}$ \\
\hline Petrolina & $168(35,9)$ & $151(32,2)$ & $164(35,0)$ & $111(23,7)$ & 468 \\
Ouricuri & $152(38,6)$ & $216(54,9)$ & $179(45,5)$ & $126(32,0)$ & 393 \\
Total & $320(37,1)$ & $367(42,6)$ & $343(39,8)$ & $237(27,5)$ & 861
\end{tabular}


dades com infestação por carrapatos $(76,9 \%)$, assim como o número de animais infestados (32,3\%). A ocorrência de dípteros hematófagos foi relatada em $100 \%$ das propriedades visitadas. Todos os carrapatos colhidos foram identificados como Rhipicephalus (Boophilus) microplus.

Os resultados verificados pela PCR demonstraram infecção por Babesia spp. em 5,8\% (8/137) das amostras dos carrapatos (2 individuais e 6 "pools"). Das oito amostras positivas, constatou-se a infecção por B. bovis em 62,5\%; e por Babesia spp. em 37,5\%. Quanto ao A. marginale, $23,3 \%$ (32/137) das amostras de carrapatos foram positivas, sendo $50 \%(16 / 32)$ provenientes de animais de Petrolina (3 individuais e 13 "pools") e 50\% (16/32) oriundos de animais de Ouricuri (4 individuais e 12 " $p o$ ols") (Quadro 2).

0 inquérito epidemiológico demonstrou que nas propriedades de Petrolina predomina a criação semi-intensiva $(57,9 \%)$ e a maioria (63\%) possui alguma área irrigada, rio ou coleção de água nas adjacências. Foi verificado que 79\% dos criadores fazem controle de ectoparasitas, mas poucos realizavam mudança de princípio ativo. Apenas $42 \%$ dos produtores apresentaram conhecimento da transmissão de doenças por carrapatos e $26 \%$ relataram o histórico de TPB na propriedade. Em Ouricuri, $100 \%$ dos criadores visitados praticavam o manejo do tipo semi-intensivo, e 61,5\% das propriedades apresentavam coleção de água. Todos os produtores realizam controle de ectoparasitas, contudo apenas $38,5 \%$ realiza o rodízio de principio ativo. A grande maioria dos criadores $(92,0 \%)$ conhecem as doenças transmitidas por carrapatos e todos eles citam a ocorrência de TPB nas suas propriedades.

Dentre as variáveis analisadas (Quadro 3), foram considerados como fatores de risco para $B$. bigemina a idade dos animais (13-60 meses) e a presença de carrapatos; para $B$. bovis a origem dos animais, ou seja, habitar no município de Ouricuri, bem como a presença de carrapatos; e para $A$. marginale a raça dos animas (mestiço e SRD) e a presença de carrapatos (Quadro 4).

Quadro 2. Detecção da infecção por hemoparasitas em carrapatos coletados de animais de Petrolina e Ouricuri, PE, pela da PCR

\begin{tabular}{lccccc}
\hline Município & $\begin{array}{c}\mathrm{N}^{\circ} \text { de amostras } \\
\text { testadas }\end{array}$ & $\begin{array}{c}\mathrm{N}^{\circ} \text { de amostras positivas } \\
\text { para Babesia spp.(\%) }\end{array}$ & $\begin{array}{c}\mathrm{N}^{\circ} \text { de amostras positivas } \\
\text { para B. bovis }(\%)\end{array}$ & $\begin{array}{c}\mathrm{N}^{\circ} \text { de amostras positivas } \\
\text { para B. bigemina }(\%)\end{array}$ & $\begin{array}{c}\mathrm{N}^{\circ} \text { de amostras positivas } \\
\text { para A. marginale }(\%)\end{array}$ \\
\hline Petrolina & 47 & $1(2,1 \%)$ & - & - & $16(34 \%)$ \\
Ouricuri & 90 & $7(7,8 \%)$ & $5(71,4 \%)$ & - & $16(17,8 \%)$ \\
Total & 137 & $8(5,8 \%)$ & $5(62,5 \%)$ & - & $32(23,3 \%)$
\end{tabular}

Quadro 3. Análise univariada dos animais com a distribuição das variáveis associadas à babesiose e anaplasmose em Petrolina e Ouricuri, PE, no período de 2011/2012

\begin{tabular}{|c|c|c|c|c|c|c|c|c|}
\hline \multirow[t]{2}{*}{ Variável } & \multirow[t]{2}{*}{ Categoria } & \multirow{2}{*}{$\begin{array}{l}\text { № total de } \\
\text { animais }\end{array}$} & \multicolumn{2}{|c|}{ B. bigemina } & \multicolumn{2}{|l|}{ B. bovis } & \multicolumn{2}{|c|}{ A. marginale } \\
\hline & & & Positivos (\%) & $P$ & Positivos (\%) & $\mathrm{p}$ & Positivos (\%) & $\mathrm{p}$ \\
\hline \multirow[t]{2}{*}{ Sexo } & Fêmea & 704 & $258(36,6)$ & & $303(43,0)$ & & $289(41,1)$ & \\
\hline & Macho & 157 & $56(35,7)$ & 0,890 & $60(38,2)$ & 0,309 & $54(34,4)$ & $0,147^{*}$ \\
\hline \multirow[t]{3}{*}{ Raça } & CRD & 220 & $91(41,4)$ & & $107(48,6)$ & & $90(40,9)$ & \\
\hline & Mestiço & 532 & $187(35,2)$ & & $219(41,2)$ & & $233(43,8)$ & \\
\hline & SRD & 109 & $36(33,0)$ & 0,199* & $37(33,9)$ & $0,030 *$ & $20(18,3)$ & $<0,001^{*}$ \\
\hline \multirow[t]{4}{*}{ Idade } & Até 12 meses & 105 & $26(24,8)$ & & $24(22,9)$ & & $34(32,4)$ & \\
\hline & 13 - 36 meses & 444 & $184(41,4)$ & & $196(44,1)$ & & $166(37,4)$ & \\
\hline & 37 - 60 meses & 162 & $62(38,3)$ & & $78(48,1)$ & & $70(43,2)$ & \\
\hline & $>60$ meses & 150 & $42(28,0)$ & $0,001^{*}$ & $65(43,3)$ & $<0,001^{*}$ & $73(48,7)$ & $0,027^{*}$ \\
\hline \multirow[t]{2}{*}{ Município } & Ouricuri & 393 & $147(37,4)$ & & $213(54,2)$ & & $179(45,5)$ & \\
\hline & Petrolina & 468 & $167(35,7)$ & 0,652 & $150(32,1)$ & $<0,001^{*}$ & $164(35,0)$ & $0,002^{*}$ \\
\hline \multirow[t]{2}{*}{ Carrapatos } & Não & 657 & $208(31,7)$ & & $214(32,6)$ & & $228(34,7)$ & \\
\hline & Sim & 204 & $106(52,0)$ & $<0,001^{*}$ & $149(73,0)$ & $<0,001^{*}$ & $115(56,4)$ & $<0,001^{*}$ \\
\hline \multirow[t]{3}{*}{ Mucosa } & Hipocorada & 181 & $54(29,8)$ & & $88(48,6)$ & & $76(42,0)$ & \\
\hline & Normal & 678 & $259(38,2)$ & & $274(40.4)$ & & $267(39,4)$ & \\
\hline & Hipercorada & 2 & $1(50,0)$ & $0,107^{*}$ & $1(50,0)$ & $0,136^{*}$ & $0(0,0)$ & 0,420 \\
\hline \multirow[t]{3}{*}{ Estado geral } & Normal & 715 & $265(37,1)$ & & $306(42,8)$ & & $277(38,7)$ & \\
\hline & Ótimo & 65 & $20(30,8)$ & & $29(44,6)$ & & $32(49,2)$ & \\
\hline & Ruim & 81 & $29(35,8)$ & 0,596 & $28(34,6)$ & 0,334 & $34(42,0)$ & 0,234 \\
\hline \multirow[t]{3}{*}{ Manejo } & Intensivo & 102 & $30(29,4)$ & & $26(25,5)$ & & $17(16,7)$ & \\
\hline & Semi-intensivo & 640 & $238(37,2)$ & & $290(45,3)$ & & $285(44,5)$ & \\
\hline & Extensivo & 119 & $46(38,7)$ & 0,275 & $47(39,5)$ & $0,001^{*}$ & $41(34,5)$ & $<0,001^{*}$ \\
\hline \multirow[t]{2}{*}{ Área irrigada } & Não & 515 & $190(36,9)$ & & $252(48,9)$ & & $240(46,6)$ & \\
\hline & Sim & 346 & $124(35,8)$ & 0,808 & $111(32,1)$ & $<0,001^{*}$ & $103(29,8)$ & $<0,001^{*}$ \\
\hline \multirow[t]{4}{*}{$\mathrm{N}^{\circ}$ de carrapatos } & Sem infestação & 658 & $208(31,6)$ & & $215(32,7)$ & & $229(34,8)$ & \\
\hline & Leve & 154 & $80(51,9)$ & & $117(76,0)$ & & $82(53,2)$ & \\
\hline & Moderada & 33 & $17(51,9)$ & & $19(57,6)$ & & $20(60,6)$ & \\
\hline & Alta & 16 & $9(56,2)$ & $<0,001^{*}$ & $12(75,0)$ & $<0,001^{*}$ & $12(75,0)$ & $<0,001^{*}$ \\
\hline \multirow[t]{2}{*}{ Carrapaticida } & Não & 93 & $25(26,9)$ & & $16(17,2)$ & & $25(26,9)$ & \\
\hline & Sim & 768 & $289(37,6)$ & $0,055^{*}$ & $347(45,2)$ & $<0,001^{*}$ & $318(41,4)$ & $0,010^{*}$ \\
\hline
\end{tabular}

*Variáveis selecionadas para a análise multivariável. 
Quadro 4. Fatores de risco para infecção por Babesia bigemina, Babesia bovis e Anaplasm marginale em animais de Petrolina e Ouricuri, PE

\begin{tabular}{lcc}
\hline Variável (categoria) & Odds ratio (IC 95\%) & $P$ \\
\hline Babesia bigemina & & \\
Idade (13 - 36 meses) & $2,11(1,30-3,45)$ & 0,003 \\
Idade (37 - 60 meses) & $1,80(1,04-3,12)$ & 0,037 \\
Carrapatos (sim) & $2,25(1,63-3,11)$ & $<0,001$ \\
Babesia bovis & & \\
Município (Ouricuri) & $2,12(1,58-2,84)$ & $<0,001$ \\
Carrapatos (sim) & $5,02(3,52-7,16)$ & $<0,001$ \\
Anaplasma marginale & & \\
Raça (mestiço) & $3,56(2,11-5,99)$ & $<0,001$ \\
Raça (SRD) & $2,28(1,29-4,04)$ & 0,005 \\
Carrapatos (sim) & $2,70(1,91-3,82)$ & $<0,001$
\end{tabular}

\section{DISCUSSÃO}

A região semiárida ocupa vasta área do território brasileiro $\left(974.752 \mathrm{~km}^{2}\right)$, abrangendo oito estados do Nordeste, além de parte da seção norte do estado de Minas Gerais. 0 clima da região é caracterizado por altas temperaturas e uma precipitação anual inferior a $800 \mathrm{~mm}$, concentrada em um período definido do ano, gerando, assim, uma estação chuvosa e uma seca. Estes fatores climáticos contribuem para a baixa produtividade da exploração agropecuária da região e influencia no status socioeconômico da população local (IBGE 2010). Associados à cobertura vegetal escassa e baixa densidade populacional de hospedeiros vertebrados, estes fatores climáticos interferem diretamente nos ciclos biológicos dos parasitas, entre eles os carrapatos. Nas áreas mais secas do semiárido o carrapato não sobrevive durante o período de seca. Entretanto, no início do período chuvoso quando bovinos com carrapatos são introduzidos nestas áreas eles restabelecem o ciclo biológico (Costa et al. 2009). Nas regiões da Zona da Mata e do Agreste do Nordeste, a ocorrência do carrapato é constante, principalmente pelas condições de umidade, favorecendo o desenvolvimento e a sobrevivência graduais dos estádios da fase não parasitária do carrapato. Aliado a isso, as temperaturas mais amenas desse período também contribuem para esse sucesso (Furlong et al. 2002, Furlong et al. 2003). Este fato tem importância direta na epidemiologia das doenças transmitidas pelos Ixodídeos, dentre elas a TPB.

A visualização de merozoítos de Babesia bigemina e Babesia bovis em esfregaços sanguíneos periféricos é facilitada em animais com sinais clínicos da doença, não sendo geralmente detectados em bovinos portadores da infecção, os quais apresentam níveis baixos de parasitemia (Jackson et al. 2001). De forma similar, na anaplasmose a bactéria geralmente é detectada no início da infecção através do exame direto, onde até $90 \%$ dos eritrócitos podem apresentar-se infectados, ou ainda pode ser detectada em casos crônicos em que os níveis de parasitemia permanecem baixos (Kieser et al. 1990).

A partir da determinação da presença de anticorpos pelo diagnóstico sorológico, as áreas de estudo foram classificadas de acordo com Sacco (2002), que caracterizam as regiões como áreas livres - aquelas onde o carrapato não ocorre devido às condições climáticas que impedem o desenvolvimento do parasito; áreas de instabilidade enzoóti- ca - onde a ocorrência de uma estação seca ou fria impede o desenvolvimento da fase de vida livre do carrapato durante parte do ano, de forma que os bovinos passem uma época do ano sem contato com o parasita ou com poucos carrapatos, não desenvolvendo imunidade duradoura contra a doença, e apresentam prevalência de animais sorologicamente positivos entre $20 \%$ e $75 \%$ (Mahoney \& Ross 1972, Araújo et al. 1997, Guimarães et al. 2011); e áreas de estabilidade enzoótica - onde a presença do carrapato ocorre durante todo o ano, fazendo com que os bovinos sejam expostos a carrapatos infectados, permanecendo imunizados.

Pelo estudo soroepidemiológico para Babesia spp. e $A$. marginale realizado em bovinos dos municípios de Petrolina e Ouricuri, foi possível demonstrar a existência desses agentes na região. Entretanto as baixas taxas de soroprevalência (frequência de anticorpos abaixo de 75\%) para $A$. marginale, $B$. bigemina e $B$. bovis verificadas por este trabalho permitem considerar ambos os municípios como áreas de instabilidade enzoótica para a TPB. Nas áreas de instabilidade enzoótica é importante o conhecimento da condição imunológica dos animais do rebanho, considerando-se a necessidade de adotar medidas de controle como adoção de manejo adequado, controle de vetores, vacinação e os riscos no transporte dos animais. Deve-se considerar que nestas áreas, a TPB pode causar grandes prejuízos aos produtores da região, devido à possibilidade da ocorrência de um grande número de casos clínicos com alta taxa de mortalidade.

Foi verificado que $84,2 \%$ das propriedades de Petrolina apresentam instabilidade para babesiose, superior à prevalência encontrada para Ouricuri $(46,2 \%)$. Este fato demonstra correlação direta da maior taxa de propriedades com infestação de carrapatos em Ouricuri $(76,2 \%)$ com maior infestação dos animais $(32,0 \%)$ neste município, quando comparada com Petrolina. Embora localizados no semiárido, os municípios estudados apresentam condições epidemiológicas diferentes para o desenvolvimento e manutenção da população de carrapatos, e consequentemente da TPB.

Os dados históricos de precipitação pluviométrica observados nos últimos 10 anos, entre 2001-2010, nos municípios de Petrolina $(38,4 \pm 38,9 \mathrm{~mm} / \mathrm{mês})$ e Ouricuri $(59,4 \pm 55,0 \mathrm{~mm} / \mathrm{mês})$, demonstram que não houve diferença estatística $(\mathrm{p} \geq 0,05)$ entre esses municípios. No entanto, se considerarmos a média histórica dos últimos dois anos, de 2010 a 2012, o município de Ouricuri apresentou uma maior precipitação $(51,9 \pm 40,7 \mathrm{~mm} / \mathrm{mês})$ quando comparada à Petrolina $(20,5 \pm 22,2 \mathrm{~mm} / \mathrm{mês})$ (Sampaio 1998, Minitab 2000, Lamepe/Itep 2013). Este fato provavelmente justifica a maior ocorrência de carrapatos nesse município, por proporcionar melhores condições climáticas para o desenvolvimento dos ixodídeos. Associado à questão climática, a utilização de medicamentos carrapaticidas em Ouricuri é realizada de forma indiscriminada, utilizando em critério subjetivo do criador, que realiza o tratamento ao observar elevação da infestação. Desta forma, os medicamentos são aplicados de forma irregular, sem a utilização de um controle estratégico, e na maioria das vezes sem acompanhamento veterinário. 
Estudos referentes à ocorrência da TPB realizados em diversas regiões semiáridas do Brasil têm encontrado situações epidemiológicas diferentes. Os dados obtidos neste estudo estão de acordo com Costa et al. $(2009,2011)$ que verificaram no sertão paraibano áreas de instabilidade enzoótica, constatando a ocorrência de surtos de TPB no final da época de chuvas nas áreas de planaltos e serras, em áreas úmidas e também em áreas irrigadas, como no município de Patos, PB. Entretanto, áreas de estabilidade enzoótica para $B$. bovis e $B$. bigemina têm sido encontradas no município de Paudalho, PE (Berto et al. 2008), em diferentes microrregiões do Estado da Bahia (Araújo et al. 1997; Barros et al. 2005) assim como em outras regiões do Brasil (Barci et al. 1994, Soares et al. 2000, Madruga et al. 2000, Trindade et al. 2010).

A detecção de área de instabilidade enzoótica para $A$. marginale verificada neste estudo, também foi observada em Sergipe (Oliveira et al. 1992), embora a maioria dos trabalhos tenha registrado estabilidade (Souza et al. 2000, 2001, Barros et al. 2005).

A susceptibilidade dos animais aos agentes da TPB é influenciada por vários fatores, destacando a idade, raça, estresse ambiental, e, nos primeiros meses de vida pela imunidade passiva (Costa et al. 2011). Geralmente, os casos clínicos são mais graves em bovinos adultos, uma vez que os animais jovens, até os seis meses de idade, apresentam maior resistência natural à infecção (Furlong et al. 2002, 2005). Em áreas de instabilidade, a ausência de vetores em determinada época do ano suspende a transmissão contínua dos agentes da TPB aos bovinos, principalmente em animais jovens, fazendo com que a soroconversão ocorra em faixas etárias elevadas. Este fato foi verificado nesse experimento, no qual animais adultos apresentaram maior prevalência de anticorpos para babesiose e anaplasmose.

As técnicas moleculares, dentre elas a PCR, apresentam maior sensibilidade e especificidade quando comparadas a outros métodos de diagnóstico, como os testes sorológicos e o exame direto através do esfregaço sanguíneo. A pesquisa do DNA do agente demonstra que os animais positivos realmente estão infectados pelo parasita, independentemente da fase da doença (Cossío-Bayúgar et al. 1997). Os pares de oligonucleotídeos utilizados neste estudo para a realização da PCR foram designados como sendo específicos para o gênero Babesia (Almeida 2011), assim como os demais oligonucleotídeos utilizados para deteç̧ão de $B$. bovis, $B$. bigemina e $A$. marginale que foram desenhados para esta finalidade (Costa 2013). A detecção da infecção nos carrapatos por Babesia spp. foi possível em 8/137 amostras analisadas, dos quais em 5/8 identificou-se que a infecção ocorrera por B. bovis. Nas demais amostras (3/8), não foi possível detectar a espécie envolvida, possivelmente devido à quantidade insuficiente de DNA nas amostras, e/ou por ter ocorrido a desnaturação do DNA presente nestas amostras ao longo dos testes realizados.

Informações sobre a epidemiologia de doenças transmitidas por carrapatos, especialmente sobre a dinâmica de transmissão da infecção por este vetor, são essenciais para elaboração de eficientes estratégias de controle (Morzaria et al. 1992). No Brasil, escassos estudos têm sido realizados utilizando carrapatos na detecção da infecção por Babesia spp. e A. marginale. Na região do semiárido nordestino pouco se conhece a respeito dos aspectos da infecção por esses hemoparasitas em carrapatos. No entanto, estudos epidemiológicos em diversos países utilizam comumente essa prática (Ica et al. 2007, M'ghirbi \& Bouattour 2008, Majláthová et al. 2011).

Dentre as variáreis associadas aos animais, a presença de carrapato foi considerada fator de risco para infecção por B. bigemina, B. bovis e A. marginale. A presença de carrapatos no município de Ouricuri mostrou-se mais frequente do que em Petrolina, o que pode ser evidenciado pela maior soroprevalência para os três patógenos observada nos animais deste município. A idade (entre 13-60 meses) foi considerada fator de risco para ocorrência da infecção por B. bigemina, devido à infecção ocorrer após o término da resistência natural, tornando os animais mais susceptíveis a infecção por este patógeno. A raça (animais mestiços e SRD) foi considerada um fator de risco associado à infecção por $A$. marginale. Habitar no município de Ouricuri foi considerado um fator de risco par a infecção por B. bovis. Desta forma, surtos de babesiose por B. bovis podem ocorrer em animais dessa área, ou de áreas indenes transportados para essa região.

\section{CONCLUSÕES}

A investigação epidemiológica da infecção por Anaplasma marginale, Babesia bigemina, Babesia bovis nos bovinos dos municípios de Petrolina e Ouricuri possibilitou confirmar a presença desses agentes e considerar que a babesiose e anaplasmose ocorrem sob a forma de instabilidade enzoótica nessas regiões, o que pode predispor a ocorrência de surtos de TPB nos municípios estudados.

O município de Ouricuri, localizado na mesorregião do Sertão Pernambucano, apresentou uma frequência de infestação por carrapatos maior que a verificada no município de Petrolina, localizado na mesorregião do São Francisco, devido à presença de condições favoráveis ao desenvolvimento dos carrapatos.

O uso indiscriminado de carrapaticida, a presença de carrapatos, a idade, a raça e o município de residência dos animais foram considerados fatores de risco para ocorrência da TPB na região estudada.

Agradecimentos.- Aos proprietários e funcionários das propriedades de Petrolina e Ouricuri, PE, pela oportunidade de desenvolvimento deste estudo, bem como a todos que ajudaram direta e indiretamente. À FACEPE (Fundação de Amparo à Ciência e Tecnologia do Estado de Pernambuco) pelo apoio financeiro ao projeto de pesquisa processo APQ 1174-5.05/10; e pela bolsa de pós-graduação processo IBPG-0095-5.05/11.

\section{REFERÊNCIAS}

Araújo E.R., Madruga C.R., Almeida M.A.O., Leal C.R.B. \& Miguita M. 1997. Levantamento sorológico de Babesia bovis e Babesia bigemina no Estado da Bahia pela imunofluorescência indireta e teste de conglutinação rápida. Revta Bras. Parasitol. Vet. 6:111-115.

Almeida A.P. 2011. Pesquisa de Rickettsia, Ehrlichia, Anaplasma, Babesia, Hepatozoon e Leishmania em Cachorro-do-mato (Cerdocyon thous) de vida livre do Estado do Espírito Santo. Dissertação de Mestrado em Epidemiologia Experimental Aplicada, Universidade de São Paulo, SP. 80p. 
Barci L.A.G., Oliveira M.R., Machado R.Z., Oliveira D.A. \& Araújo Filho R.S. 1994. Epidemiologia da babesiose bovina no Estado de São Paulo. I. Estudo em rebanhos produtores de leite tipo B do município de Pindamonhagaba, Vale do Paraíba. Revta Bras. Parasitol. Vet. 3:79-82.

Barros S.L., Madruga C.R., Araújo F.R., Menk C.F., De Almeida M.A., Melo E.P. \& Kessler R.H. 2005. Serological survey of Babesia bovis, Babesia bigemina, and Anaplasma marginale antibodies in cattle from the semi-arid region of the state of Bahia, Brazil, by enzyme-linked immunosorbent assays. Mem. Inst. Oswaldo Cruz 100:613-617.

Bastos C.V., Passos L.M., Facury-Filho E.J., Rabelo E.M., De La Fuente J. \& Ribeiro M.F. 2010. Protection in the absence of exclusion between two Brazilian isolates of Anaplasma marginale in experimentally infected calves. Vet. J. 186:374-378.

Berto R.S., Faustino M.A.G., Melo L.E.H., Alves L.C., Madruga C.R., Almeida M.A.O., Ramos C.A.N., Tenório T.G.S. \& Silva F.F. 2008. Frequência de anticorpos IgG anti-Babesia bovis e anti-Babesia bigemina em bovinos no Município do Paudalho, Zona da Mata do Estado de Pernambuco. Med. Vet. 2:9-12.

Bock R., Jackson L., De Vos A. \& Jorgensen W. 2004. Babesiosis of cattle. Parasitol. 129:247-269.

Böse R., Jorgensen W.K., Dalgliesh R.J., Friedhoff K.T. \& De Vos A.J. 1995. Current state and future trends in the diagnosis of babesiosis. Vet. Parasitol. 57:61-74.

Cossío-Bayúgar R., Rodríguez S.D., García-Ortiz M.A., García-Tapia D. \& Aboytes-Torres R. 1997. Bovine anaplasmosis prevalence in northern Veracruz state, Mexico. Prev. Vet. Med. 32:165-170.

Costa V.M.M., Simões S.V.D. \& Riet-Correa F. 2009. Doenças parasitárias em ruminantes no semi-árido brasileiro. Pesq. Vet. Bras. 29:563-568.

Costa V.M.M, Rodrigues A.L., Medeiros J.M.A., Labruna M.B., Simões S.V.D. \& Riet-Correa F. 2011. Tristeza parasitária bovina no Sertão da Paraíba. Pesq. Vet. Bras. 31:239-243.

Costa V.M.M. 2013. Estudo epidemiologico da Tristeza Parasitaria Bovina no estado da Paraíba. Tese de Doutorado em Medicina Veterinária, Centro de Saúde e Tecnologia Rural, Universidade Federal de Campina Grande, Patos, PB. 107p.

Costa-Júnior L.M., Rabelo E.M., Martins Filho O.A. \& Ribeiro M.F. 2006. Comparison of different direct diagnostic methods to identify Babesia bovis and Babesia bigemina in animals vaccinated with live attenuated parasites. Vet. Parasitol. 139:231-236.

Dreher U.M., Hofmann-Lehmann R., Meli M.L., Regula G., Cagienard A.Y., Stärk K.D., Doherr M.G., Filli F., Hässig M., Braun U., Kocan K.M. \& Lutz H. 2005. Seroprevalence of anaplasmoses among cattle in Switzerland in 1998 and 2003: No evidence of an emerging disease. Vet. Microbiol. 25:71-79.

Furlong J., Chagas A.C.S. \& Nascimento C.B. 2002. Comportamento e ecologia de larvas do carrapato Boophilus microplus em pastagem de Brachiariadecumbens. Braz. J. Vet. Res. Anim. Sci. 39:213-217.

Furlong J., Martins J.R.S. \& Prata M.C.A. 2003. Carrapato dos bovinos: controle estratégico nas diferentes regiões brasileiras. Comum. Téc. 36), Embrapa Gado de Leite, Juiz de Fora. 6p.

Furlong J., Martins J.R.S. \& Prata M.C.A. 2005. Carrapatos: problemas e soluções. Embrapa Gado de Leite, Juiz de Fora. 65p.

Guglielmone A.A. 1995. Epidemiology of babesiosis and anaplasmosis in South and Central America. Vet. Parasitol. 57:109-119.

Guimarães M.A., Carvalho A.H.O., Daher D.O., Rocha C.M.B.M. \& Hirsch C. 2011. Soroprevalência e fatores de risco para Babesia bovis em rebanhos leiteiros na Região Sul de Minas Gerais. Ciênc. Agrotec. 35:826-832.

Horta M.C., Labruna M.B., Pinter A., Linardi P.M. \& Schumaker T.T.S. 2007. Rickettsia infection in five areas of the state of São Paulo, Brazil. Mem. Inst. Osw. Cruz 2:793-801.

IBGE 2010. Produção da pecuária municipal 2010. Vol.38. Instituto Brasileiro de Geografia e Estatística, Rio de Janeiro.
IICA 1987. Técnicas para el diagnóstico de babesiosis y anaplasmosis bovina. Instituto Interamericano de Cooperación para la Agricultura, San José. 79p.

Ica A., Vatansever Z., Yildirim A., Duzlu O. \& Inci A. 2007. Detection of Theileria and Babesia species in ticks collected from cattle. Vet. Parasitol. 148:156-160.

Jackson L.A., Waldron S.J., Weier H.M., Nicoll C.L. \& Cooke B.M. 2001. Babesia bovis: Culture of laboratory adapted parasite lines and clinical isolates in a chemically defined medium. Exp. Parasitol. 99:168-174.

Kieser S.T., Eriks I.E. \& Palmer G.H. 1990. Cyclic rickettsemia during persistent Anaplasma marginale infection in cattle. Infect. Immun. 58:1117119.

Kocan K.M., De La Fuente J., Blouin E.F., Coetzee J.F. \& Ewing S.A. 2010. The natural history of Anaplasma marginale. Vet. Parasitol. 167:95-107.

Lamepe/Itep 2013. Disponível em <http://www.itep.br/index.php? option $=$ com_content $\&$ view $=$ article\&id $=102 \&$ Itemid $=162>$ Acessado em may 23, 2013.

Madruga C.R., Honer M.R., Andreotti M.R. \& Araújo F.R. \& Santarém V. 1993. Prevalência de Anaplasma marginale em três regiões do estado da Paraíba. Anais VI Congresso Internacional de Medicina Veterinária em Língua Portuguesa, p.350-352.

Madruga C.R., Araújo F.R., Marques A.P.C., Carvalho C.M.E., Cusinato F.Q., Crocci A.J., Kessler R.H. \& Miguita M. 2000. Desenvolvimento de uma prova de imunoadsorção enzimática para detecção de anticorpos contra Babesia bovis. Pesq. Vet. Bras. 20:167-170.

Mahoney D.F. \& Ross D.R. 1972. Epizootiological factors in the control of bovine babesiosis. Aust. Vet. J. 48:292-298.

Majláthová V., Majláth I., Vichová B., Gul'ová I., Derdáková M., Sesztáková E. \& Pet'ko B. 2011. Polymerase chain reaction Confirmation of Babesia canis canis and Anaplasma phagocytophilum in Dogs Suspected of Babesiosis in Slovakia. Vector Borne Zoonotic Dis. 11:1447-4451.

M'ghirbi Y. \& Bouattour A. 2008. Detection and molecular characterization of Babesia canis vogeli from naturally infected dogs and Rhipicephalus sanguineus ticks in Tunisia. Vet. Parasitol. 152:1-7.

Minitab 2000. The student edition of MINITAB statistical software adapted for education: 13.0 release; user's manual. Wesley, New York. 624p.

Morzaria S., Katende J., Kairo A., Nene V. \& Musoke A., 1992. New methods for the diagnosis of Babesia bigemina infection. Mem. Inst. Oswaldo Cruz 87:201-205.

Oliveira A.A., Pedreira P.A.S. \& Almeida M.F.R.S. 1992. Doenças de bezerros. II. Epidemiologia da anaplasmose no estado de Sergipe. Arq. Bras. Med. Vet. Zootec. 44:377-386.

Sacco A.M.S. 2002. Profilaxia da Tristeza Parasitária Bovina: por quê, quando e como fazer. Circ. Téc. 28, Embrapa Pecuária Sul, Bagé.12p.

Sampaio I.B.M. 1998. Estatística Aplicada à Experimentação Animal. Fundação de Ensino e Pesquisa em Medicina Veterinária e Zootecnia, Belo Horizonte. 221p.

Soares C.O., Souza J.C.P., Madruga C.R., Madureira R.C., Massard C.L. \& Fonseca A.H. 2000. Seroprevalence of Babesia bovis in cattle in the Norte Fluminense region. Pesq. Vet. Bras. 20:75-79.

Souza J.C.P., Soares C.O., Massard C.L., Scofield A. \& Fonseca A.H. 2000. Soroprevalência de Anaplasma marginale em bovinos na mesorregião Norte Fluminense. Pesq. Vet. Bras. 20:97-101.

Souza J.C.P., Soares C.O., Madruga C.R. \& Massard C.L. 2001. Prevalência de anticorpos anti-Anaplasma marginale (Rickettsiales: Anaplasmataceae) em bovinos na mesorregião do Médio Paraíba. Ciência Rural 31:309314.

Trindade H.I., Silva G.R.A., Teixeira M.C.A., Sousa M.G., Machado R.Z., Freitas F.L.C. \& Almeida K.S. 2010. Detection of antibodies against Babesia bovis and Babesia bigemina in calves from the region of Araguaína, State of Tocantins, Brazil. Revta Bras. Parasitol. Vet. 19:169-173. 